Provided for non-commercial research and education use. Not for reproduction, distribution or commercial use.

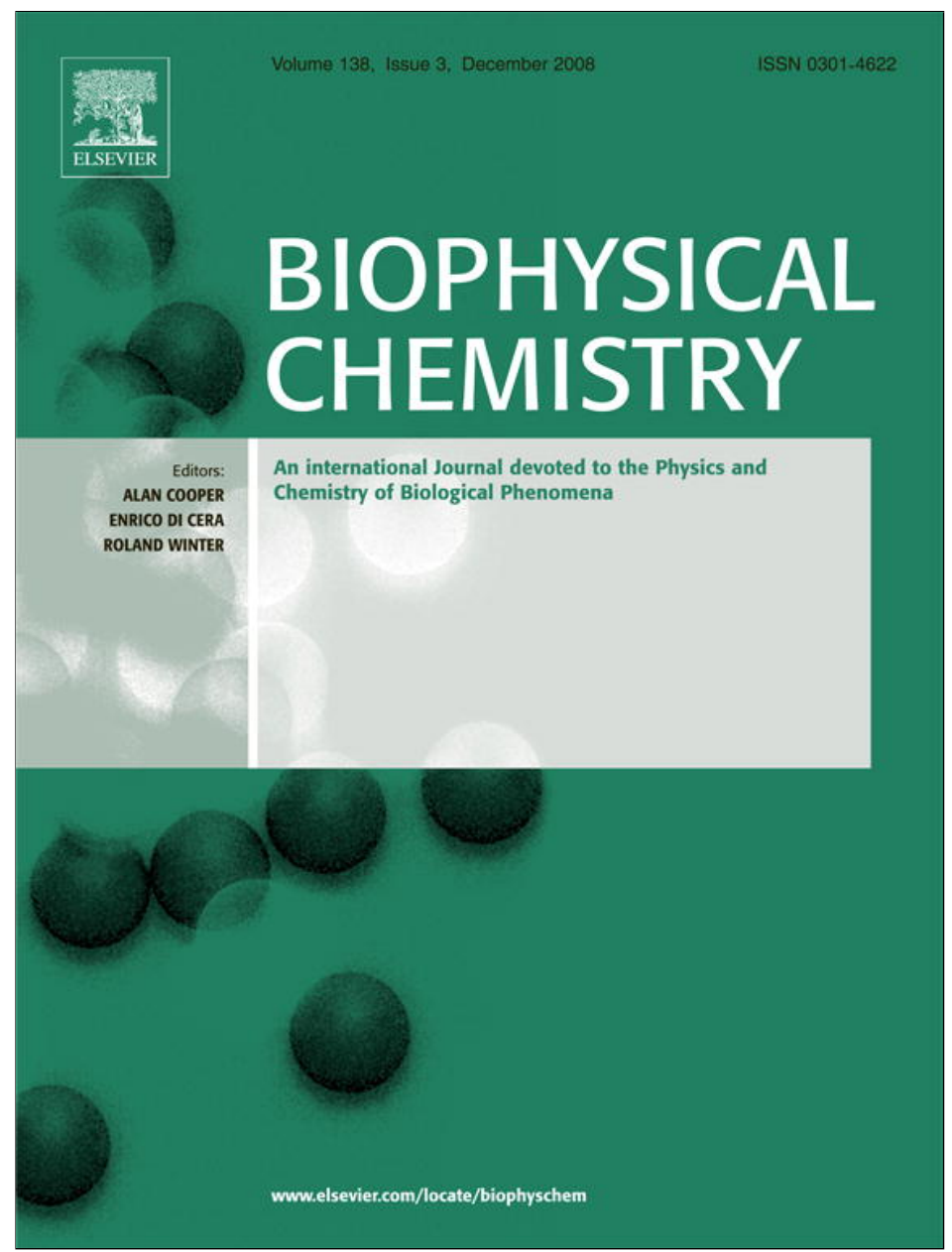

This article appeared in a journal published by Elsevier. The attached copy is furnished to the author for internal non-commercial research and education use, including for instruction at the authors institution and sharing with colleagues.

Other uses, including reproduction and distribution, or selling or licensing copies, or posting to personal, institutional or third party websites are prohibited.

In most cases authors are permitted to post their version of the article (e.g. in Word or Tex form) to their personal website or institutional repository. Authors requiring further information regarding Elsevier's archiving and manuscript policies are encouraged to visit:

http://www.elsevier.com/copyright 


\title{
A new rapid and simple method to determine the kinetics of electrode reactions of biologically relevant compounds from the half-peak width of the square-wave voltammograms
}

\author{
Rubin Gulaboski a,b,*, Milivoj Lovrić ${ }^{c}$, Valentin Mirceski ${ }^{\mathrm{b}}$, Ivan Bogeski ${ }^{\mathrm{a}}$, Markus Hoth ${ }^{\mathrm{a}}$ \\ a Department of Biophysics, Saarland University, Homburg, Germany \\ ${ }^{b}$ Institute of Chemistry, Faculty of Natural Sciences and Mathematics, Skopje, Republic of Macedonia \\ ${ }^{\text {c }}$ Rudjer Boskovic Institute, Zagreb, Croatia
}

\section{A R T I C L E I N F O}

\section{Article history:}

Received 25 August 2008

Received in revised form 15 September 2008

Accepted 15 September 2008

Available online 26 September 2008

\section{Keywords:}

Charge-transfer kinetics

Standard rate constant

Square-wave voltammetry

Half-peak width

Theoretical calculations

Protein-film voltammetry

\begin{abstract}
A B S T R A C T
A new method is introduced to determine the kinetic parameters of electron transfer reactions of biologically important compounds, based on the measurements of the half-peak width $\left(\Delta E_{\mathrm{p} / 2}\right)$ of the square-wave voltammograms. A simple surface (diffusionless) redox reaction, and a simple electrode reaction occurring from dissolved state are considered as model systems. In the region of quasireversible electron transfer, the half-peak widths of theoretical square-wave voltammograms are linear functions of the logarithm of the dimensionless kinetic parameter $\ln (K)$ that characterizes the rate of the electron transfer reaction. The dimensionless kinetic parameter $K$ is defined as $K=k_{\mathrm{s}}(f D)^{-0.5}$ for the redox reaction taking place from dissolved state, whereas for the surface redox reaction $K$ is defined as $K=k_{\mathrm{s}} / f\left(k_{\mathrm{s}}\right.$ is the standard rate constant of electron transfer, $f$ is the SW frequency, and $D$ is the diffusion coefficient). A set of linear regression equations for the dependences $\Delta E_{\mathrm{p} / 2}$ vs. $\ln (K)$ are derived, which can be used for rapid and precise determination of the charge-transfer kinetic parameters. The estimated values for the standard rate constants of various biologically relevant redox systems using this approach are in very good agreement with the experimental values determined by other square-wave voltammetric methods. The square-wave voltammetric half-peak width method can be used as a simple and reliable alternative to other voltammetric methods developed for the kinetic characterization of electron transfer rates.
\end{abstract}

(C) 2008 Elsevier B.V. All rights reserved.

\section{Introduction}

The electron (or charge) transfer reactions are central to the function of proteins and other redox-active compounds in many biological processes. This is well known in bioenergetics: photosynthesis and respiration realize energy conversion through a complex sequence of electron transfer reactions. However, electron transfer also takes place in many other biological processes ranging from cell defense to gene control. The rate of electron transfer from a donor $D$ to an acceptor $\mathrm{A}$ is a key parameter that determines particular biological function, and much effort has been made to relate the rate of electron transfer to structural and thermodynamic features of the compounds of interest. In the last 20 years the square-wave voltammetry (SWV) emerged as an inevitable instrumental tool in numerous research laboratories dealing with biochemical, physiological, physical, chemi-

\footnotetext{
* Corresponding author. Institut für Biophysik, Gebäude 58, Universität des Saarlandes, D-66421 Homburg/Saar, Germany. Tel.: +49 6841 1626452; fax: +49 6841 1626060 .

E-mail address: rubingulaboski@excite.com (R. Gulaboski).
}

cal, environmental and medical issues [1-6]. The electrochemical analysis of various biologically relevant redox-active compounds with square-wave voltammetry attracted significant attention, mainly because of the ability of SWV to gain detailed insight into mechanisms of chemical reactions coupled to electron transfer, as well as due to appropriateness of the technique for sensory biotechnology [3,7-9]. The main attributes and the most important theoretical and experimental achievements of the SWV have been thoroughly reviewed in a very recent monograph [3]. Quantifying the strengths of interactions between biologically important compounds, and revealing the mechanistic pathways of many proteins and enzymes attached to the surface of the working electrodes are just some of the new exciting fields in which square-wave voltammetry has been explored as a simple and powerful tool [2,3,8-11]. The SWV technique allows accurate quantification of various kinetic and thermodynamic parameters connected to electron transfer reactions of many redox-active compounds in very elegant ways $[1-3,12,13]$. Considering the electrode reaction of a single compound, the main physical parameters that describe the electron transfer reaction between the electrode and the investigated compound are: the standard redox potential $E^{\circ}$ (which is tightly connected to the magnitude of the energetic barrier of electron 
transfer), the number of exchanged electrons involved in the elementary act of electrochemical transformation $n$, the electron transfer coefficient $\alpha$ (i.e. the symmetry factor of the energetic barrier [2]), and the standard rate constant of electron transfer $k_{\mathrm{s}}$. The recent theoretical considerations of various redox systems analyzed by SWV permitted valuable information about the kinetic and thermodynamic parameters of electron transfer steps by various redox systems [2,3,14-24]. To date, the kinetics of electron transfer reactions have been most commonly characterized by cyclic voltammetry $[2,25,26]$. The kinetic characterization with the square-wave voltammetry has become particularly interesting due to the simplicity and accuracy of the developed methods [2,3,14-24]. While the peak potentials (and peak-to-peak separation) as a function of the SW frequency have commonly been used to determine the kinetics of redox reactions from the dissolved state $[1-3,13]$, the phenomenon of "quasireversible maximum" (based on the peak-current measurements) has emerged as a simple and viable method to determine kinetic parameters of surface-confined redox reactions [3,12,19-24]. In the present paper, we present theoretical results that are related to the measuring of kinetic parameters of the electron transfer reactions, in which the half-peak width of the net square-wave voltammograms is the main studied feature. To the best of our knowledge, there is no paper in the literature about the kinetic measurements extracted from the half-peak widths of the square-wave voltammograms. We develop a new theoretical method to determine the kinetics of electrode reactions from the halfpeak width of the square-wave voltammograms. Redox reactions in a dissolved state and surface redox reactions of strongly adsorbed redox couple (which can be considered as a diffusionless redox system) were analyzed. The new method is a simple and viable alternative for quick and accurate assessment of the physical parameters related to the electron transfer reactions of redox systems.

\section{Results and discussions}

Theoretical net SW voltammograms are bell-shaped curves characterized by peak potential $\Delta E_{\mathrm{p}}$, peak current $\Psi_{\mathrm{p}}$, and half-peak width $\Delta E_{\mathrm{p} / 2}$ (Fig. 1). The half-peak width is an item defined as the width (measured in millivolts) at the half-height of the net SW voltammetric peak. All these parameters of the voltammetric curves are a function of the potential modulation parameters (frequency $f$, amplitude $E_{\mathrm{sw}}$, and potential increment $\Delta E$ ), the number of exchanged electrons $n$, the electron transfer coefficient $\alpha$, and the temperature $T$, as well as of the dimensionless electrode kinetic parameter $K$. For redox reactions taking place from a dissolved state, the dimensionless kinetic parameter $K$ is defined as $K=k_{\mathrm{s}}(f D)^{-0.5}$, while for the surface redox reaction $K$ is defined as $K=k_{\mathrm{s}} \mid f$. By $k_{\mathrm{s}}$ we assign the standard rate constant of electron transfer $\left(k_{\mathrm{s}}\right.$ is given in $\mathrm{cm} \mathrm{s}^{-1}$ for reaction from the dissolved state and in $\mathrm{s}^{-1}$ for surface redox reactions), while $D\left(\mathrm{~cm}^{2} \mathrm{~s}^{-1}\right)$ is the common diffusion coefficient of both species of the dissolved redox couple. Detailed studies of the features of simple surface redox reaction and redox reaction from

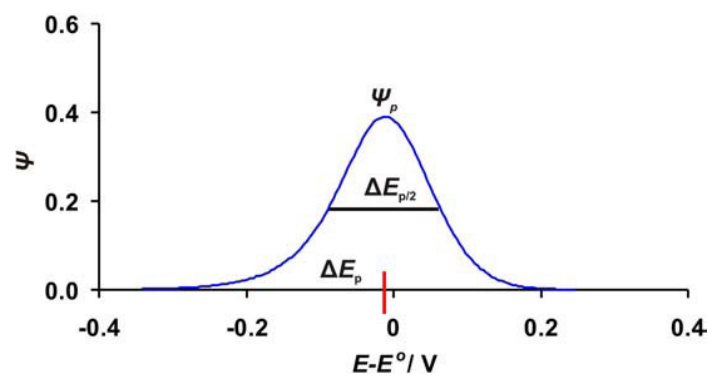

Fig. 1. Theoretical net square-wave voltammogram of a simple redox reaction taking place from dissolved state. The simulation conditions were: $n=1, E_{\mathrm{sw}}=50 \mathrm{mV} ; \Delta E=4 \mathrm{mV}$, $\alpha=0.4 ; T=298 \mathrm{~K}, D=5 \times 10^{-6} \mathrm{~cm}^{2} \mathrm{~s}^{-1}$. The value of the kinetic parameter was $\ln (K)=$ $-1.21$

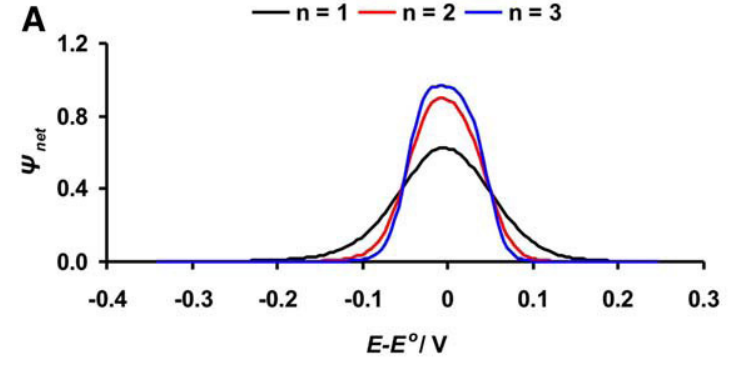

B $-n=1-n=1-n=2-n=2-n=3-n=3$

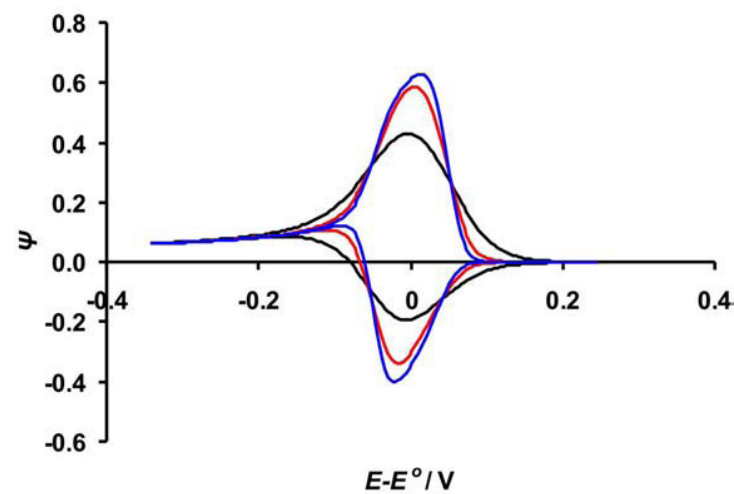

Fig. 2. Redox reaction from dissolved state: A) The net square-wave voltammograms calculated as a function of the number of exchanged electrons. B) Forward and backward components corresponding to the net square-wave voltammograms. $\ln (K)=-0.068$, while all the other conditions were same as in Fig. 1 .

the dissolved state related to the influence of the kinetic parameter $K$, $E_{\mathrm{sw}}, \alpha$, and $n$ under conditions of square-wave voltammetry can be found elsewhere $[3,12,13]$. In this work, we focus on the influence of the kinetic parameters of the electron transfer reaction on the half-peak widths of theoretical square-wave voltammograms.

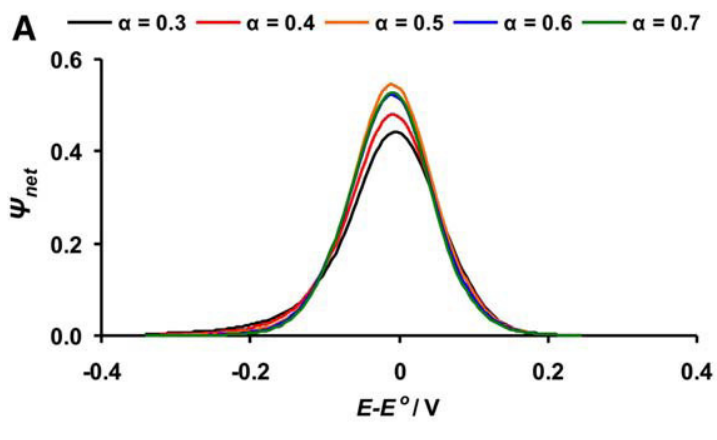

B

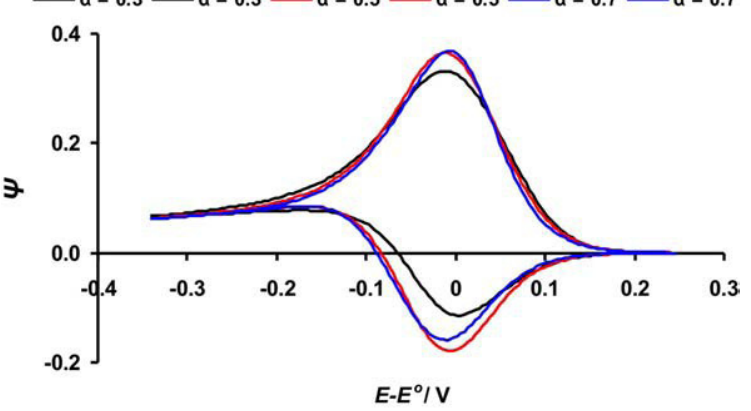

Fig. 3. Redox reaction from dissolved state: A) The net square-wave voltammograms calculated as a function of the electron transfer coefficient $\alpha$. B) Forward and backward components corresponding to the net square-wave voltammograms. $\ln (K)=-0.83$, while all the other conditions were same as those in Fig. 1. 


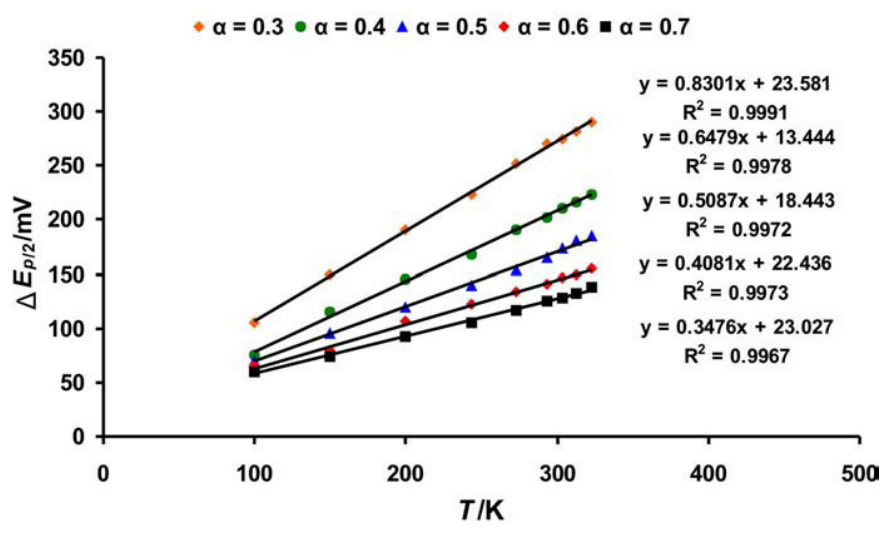

Fig. 4. Redox reaction from dissolved state: Temperature dependence of the net SW halfpeak widths $\Delta E_{\mathrm{p} / 2}$ simulated for various electron transfer coefficients in the region of very slow electron transfer. $\ln (K)=-4.0$, while all the other simulation details are same as those in Fig. 1.

2.1. Analysis of the half-peak width of the SW voltammograms in the case of an electrode reaction taking place from dissolved state

In this case, we consider simple redox reaction taking place from dissolved state that can be described by the following reaction scheme:

$\mathrm{A}_{(\text {dissolved })}+n \mathrm{e}^{-} \Leftrightarrow \mathrm{B}_{(\text {dissolved })}$

The half-peak width of the SW voltammograms of a redox reaction from dissolved state (at constant temperature) is influenced by the normalized square-wave amplitude $n E_{\mathrm{sw}}$, the electron transfer coefficient $\alpha$, and the dimensionless kinetic parameter $K$. The sensitivity of
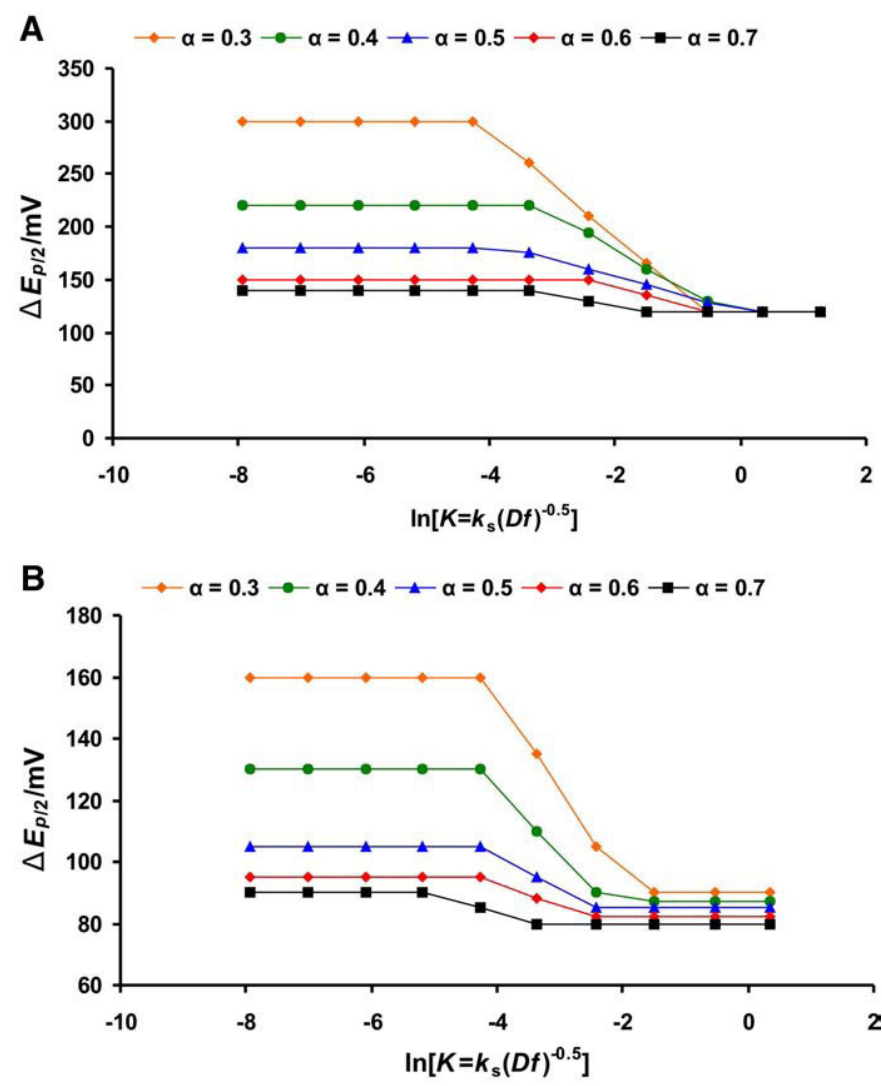

Fig. 5. Redox reaction from dissolved state: Theoretical dependence of the half-peak widths of the net square-wave voltammograms on $\ln (K)$ simulated for several values of the electron transfer coefficients $\alpha$. A) $n=1$ and B) $n=2$. All the other simulation details are same as those in Fig. 1. the half-peak width to the number of exchanged electrons $n$ and the electron transfer coefficient $\alpha$ has been briefly mentioned in the work of O'Dea and Osteryoungs [12,13].

In the next set of figures, we show in more details how the SW voltammetric responses are affected by $n$ and $\alpha$. In Fig. 2A, the net square-wave voltammograms calculated for 3 different values of $n$ are shown. Increasing the number of electrons involved in the direct act of the electrochemical transformation is followed by a decrease of the half-peak width of the simulated SW voltammograms. This feature is a direct consequence of the sensitivity of the shape of forward and backward components of the corresponding square-wave voltammetric responses to $n$. Both, forward and backward component are getting much narrower as $n$ increases (see Fig. 2B). Since the net current in SWV is defined as a difference between the forward and the backward current components, the shape of the net SWV peak always reflects changes of the forward and/or backward SW components. Besides the number of electrons, the half-peak widths of theoretical square-wave voltammograms are also sensitive to the charge-transfer coefficient $\alpha$ (see Fig. 3A and B). Increase of the value of electron transfer coefficient $\alpha$ decreases the peak-to-peak separations between the forward and backward current components (Fig. 3A), which again results in a decrease of the net half-peak widths (Fig. 3B).

\subsubsection{Determination of charge-transfer coefficient alpha $(\alpha)$ from the net} square-wave voltammograms

Most commonly, for a given number of electrons exchanged $n$, the half-peak width of the net voltammograms of an irreversible
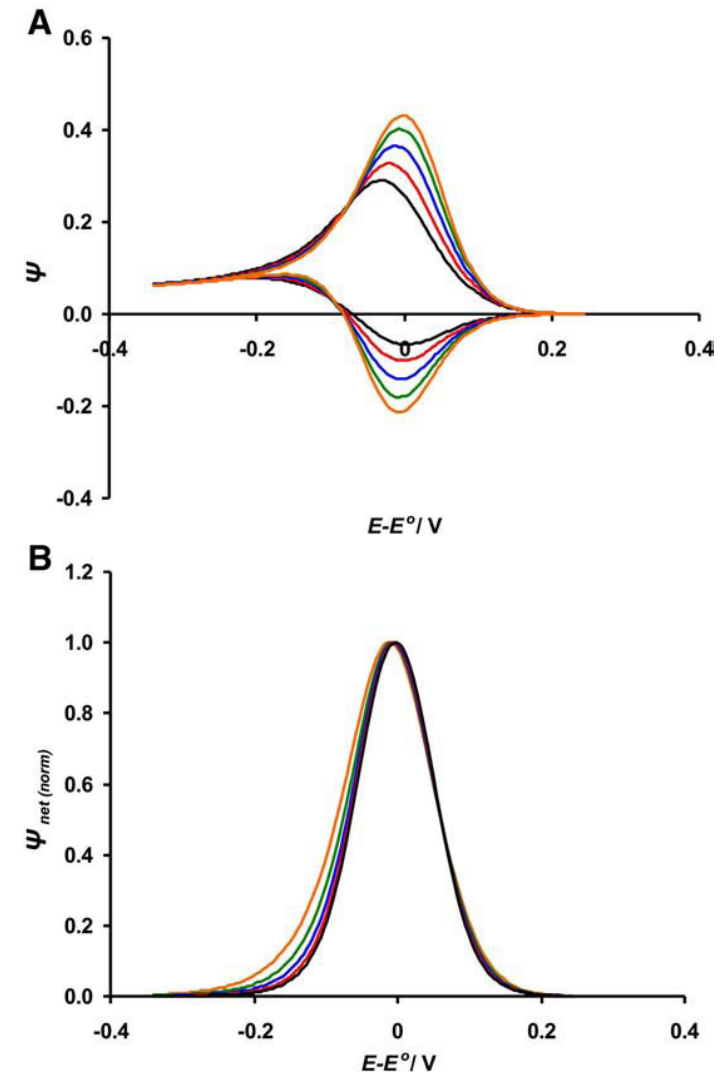

Fig. 6. Redox reaction from dissolved state: A) Effect of the kinetic parameter $K$ to the shape of the forward and backward current components of the simulated voltammograms. The net SW voltammograms in figure B) are normalized, and they show the effect of $K$ to their half-peak width. $\ln (K)=-1.21$ (pink), -0.83 (green), -0.45 (blue) -0.07 (red) and 0.31 (black). All the other simulation details are same as those in Fig. 1 (For interpretation of the references to color in this figure legend, the reader is referred to the web version of this article.) 
Table 1

Simple redox reaction from dissolved state

A. Equations of the linear dependences between the SW half-peak width $\Delta E_{\mathrm{p} / 2}$ and ln $(K)$ in quasireversible region. SW voltammograms were simulated for $T=298 \mathrm{~K}$, $\Delta E=4 \mathrm{mV}, n=1$

\begin{tabular}{lll}
\hline$n E_{\mathrm{sw}} / \mathrm{mV}$ & $\alpha$ & Equation of the dependence $\Delta E_{\mathrm{p} / 2}-\ln (K)$ \\
\hline 30 & 0.3 & $\Delta E_{\mathrm{p} / 2} / \mathrm{mV}=-43.73 \ln (K)+105$ \\
& 0.4 & $\Delta E_{\mathrm{p} / 2} / \mathrm{mV}=-37.94 \ln (K)+105$ \\
& $\Delta E_{\mathrm{p} / 2} / \mathrm{mV}=-27.85 \ln (K)+105$ \\
& 0.6 & $\Delta E_{\mathrm{p} / 2} / \mathrm{mV}=-15.87 \ln (K)+105$ \\
40 & 0.7 & $\Delta E_{\mathrm{p} / 2} / \mathrm{mV}=-10.90 \ln (K)+105$ \\
& 0.3 & $\Delta E_{\mathrm{p} / 2} / \mathrm{mV}=-49.50 \ln (K)+115$ \\
& 0.4 & $\Delta E_{\mathrm{p} / 2} / \mathrm{mV}=-32.10 \ln (K)+115$ \\
& 0.5 & $\Delta E_{\mathrm{p} / 2} / \mathrm{mV}=-16.05 \ln (K)+115$ \\
50 & 0.6 & $\Delta E_{\mathrm{p} / 2} / \mathrm{mV}=-14.62 \ln (K)+115$ \\
& 0.7 & $\Delta E_{\mathrm{p} / 2} / \mathrm{mV}=-49.23 \ln (K)+115$ \\
& 0.3 & $\Delta E_{\mathrm{p} / 2} / \mathrm{mV}=-32.06 \ln (K)+120$ \\
& 0.4 & $\Delta E_{\mathrm{p} / 2} / \mathrm{mV}=-16.70 \ln (K)+120$ \\
& 0.5 & $\Delta E_{\mathrm{p} / 2} / \mathrm{mV}=-15.78 \ln (K)+120$ \\
& $\Delta E_{\mathrm{p} / 2} / \mathrm{mV}=-10.60 \ln (K)+120$
\end{tabular}

B. $n=2$; All the other conditions are same as those by panel A

\begin{tabular}{lll}
\hline 30 & 0.3 & $\Delta E_{\mathrm{p} / 2} / \mathrm{mV}=-32.60 \ln (K)+70$ \\
0.4 & $\Delta E_{\mathrm{p} / 2} / \mathrm{mV}=-16.30 \ln (K)+70$ \\
0.5 & $\Delta E_{\mathrm{p} / 2} / \mathrm{mV}=-10.80 \ln (K)+70$ \\
& $\Delta E_{\mathrm{p} / 2} / \mathrm{mV}=-08.70 \ln (K)+70$ \\
& 0.6 & $\Delta E_{\mathrm{p} / 2} / \mathrm{mV}=-05.40 \ln (K)+70$ \\
& 0.7 & $\Delta E_{\mathrm{p} / 2} / \mathrm{mV}=-32.60 \ln (K)+75$ \\
& 0.3 & $\Delta E_{\mathrm{p} / 2} / \mathrm{mV}=-19.00 \ln (K)+75$ \\
& 0.4 & $\Delta E_{\mathrm{p} / 2} / \mathrm{mV}=-10.85 \ln (K)+75$ \\
& 0.5 & $\Delta E_{\mathrm{p} / 2} / \mathrm{mV}=-08.70 \ln (K)+75$ \\
& 0.6 & $\Delta E_{\mathrm{p} / 2} / \mathrm{mV}=-05.40 \ln (K)+75$ \\
& $\Delta E_{\mathrm{p} / 2} / \mathrm{mV}=-32.56 \ln (K)+80$ \\
& 0.3 & $\Delta E_{\mathrm{p} / 2} / \mathrm{mV}=-21.80 \ln (K)+80$ \\
& 0.4 & $\Delta E_{\mathrm{p} / 2} / \mathrm{mV}=-10.85 \ln (K)+80$ \\
& 0.5 & $\Delta E_{\mathrm{p} / 2} / \mathrm{mV}=-07.05 \ln (K)+80$ \\
0.6 & $\Delta E_{\mathrm{p} / 2} / \mathrm{mV}=-05.60 \ln (K)+80$ \\
& 0.7 &
\end{tabular}

electrode reaction depends mainly on the electron transfer coefficient $\alpha[1-3,13]$. In the region of a very sluggish (irreversible) electron transfer, the half-peak width $\Delta E_{\mathrm{p} / 2}$ is a linear function of the temperature. The magnitude of the half-peak widths decreases linearly with the temperature, with a slope being inversely proportional of $\alpha$ (see Fig. 4). The dependence $\Delta E_{\mathrm{p} / 2} v s$. $T$ in the irreversible region is defined as $\Delta E_{\mathrm{p} / 2}=\left(z \frac{R}{\alpha n F}\right) T$, where the factor $z$ is a constant depending on $E_{\mathrm{sw}}$. Since the half-peak width is independent on the electrode kinetic parameter $K\left(K=k_{\mathrm{s}}(D f)^{-0.5}\right)$ in the irreversible kinetic region $(\ln (K)<-3)[3,13]$, the electron transfer coefficient can be estimated from the analysis of $\Delta E_{\mathrm{p} / 2} v s$. T (see Fig. 4). At this stage, it is worth to stress that the temperature dependence should be done in some reasonable temperature interval (i.e. not very drastic changes in $T$ ) in order to avoid the strong changes of the value of the diffusion coefficient (and strong changes in the values of $K$, correspondingly), which is, indeed, temperature sensitive parameter. It is worth mentioning, that in the real experiment, if a quasireversible electrode reaction is being considered, the transfer of the electrode system into the irreversible kinetic region can be achieved by an increase of the frequency of the potential modulation.

\subsubsection{Effect of the kinetic parameter K to the half-peak width of square-wave voltammograms}

The calculated curves representing the effect of the dimensionless kinetic parameter $K$ on the half-peak widths for several values of the electron transfer coefficient $\alpha$ are shown in Fig. 5A and B (for $n=1$ and $n=2$, respectively). In all cases, the dependences between $\Delta E_{\mathrm{p} / 2}$ and $\ln (K)$ are sigmoidal. In the region of very sluggish electron transfer (roughly for $\ln (K)<-3$ ) as well as in the region of very fast electron transfer $(\ln (K)>0)$, the half-peak width is insensitive to the kinetic parameter $K$. However, in the region of modest electron transfer (the so-called "quasireversible region"), significant changes

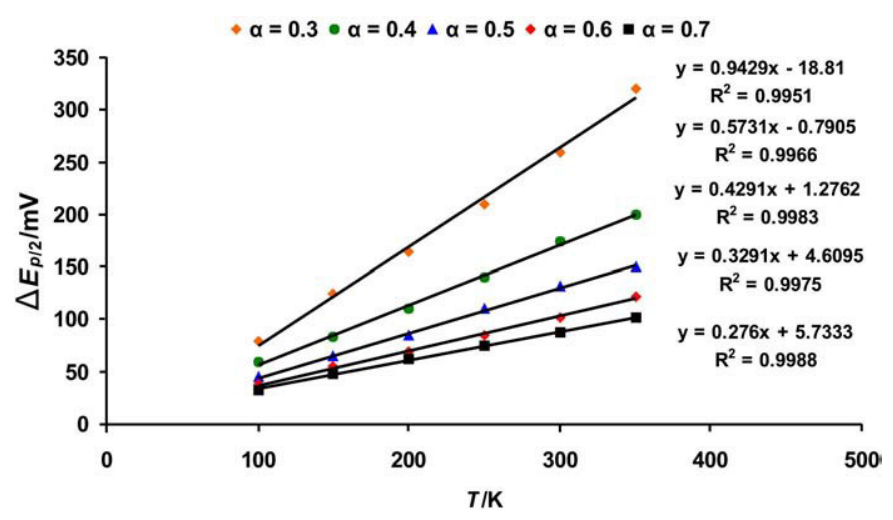

Fig. 7. Surface redox reaction: Temperature dependence of the net SW half-peak widths $\Delta E_{\mathrm{p} / 2}$ simulated for various electron transfer coefficients in the region of very slow electron transfer. $\ln (K)=-3.0, n=1$, while all the other simulation details are same as those in Fig. 8.

in the half-peak widths occur. Increasing of the value of $K$ in the quasireversible region is followed by a decrease of the magnitude of the half-peak width. The origin of such behaviour is revealed by analyzing the properties of the forward and backward components of the SW voltammograms as a function of $K$ (Fig. 6A). As the value of $K$ increases, the peak-to-peak separation between the forward and the backward current components decrease. This results in a decrease of the half-peak width of the net SW voltammograms in the quasireversible kinetic region (see Fig. 6B). In the quasireversible region, the magnitude of the half-peak width is a linear function of $\ln (K)$ (see Fig. 5A, B), with a slope being inversely proportional to the electron transfer coefficient $\alpha$. The equations corresponding to the theoretical linear dependences between
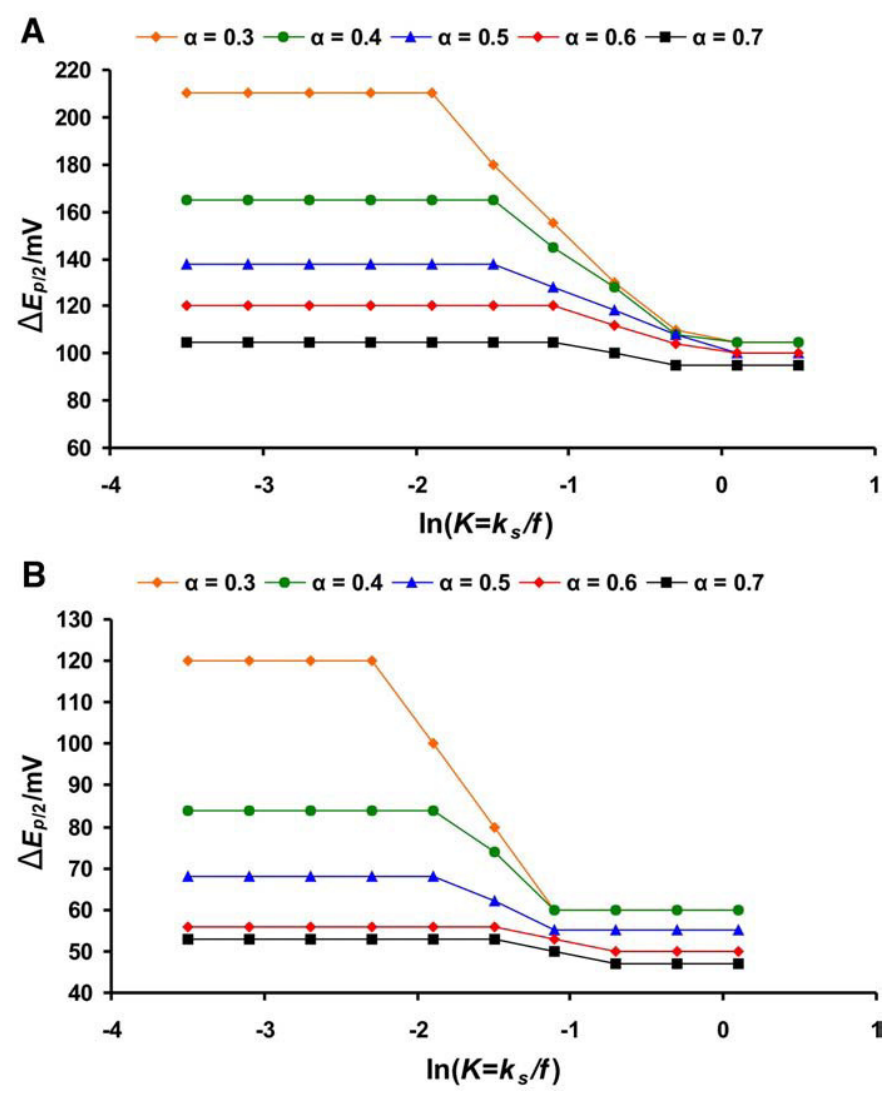

Fig. 8. Surface redox reaction: Theoretical dependence of the half-peak widths of the net square-wave voltammograms on $\ln (K)$ simulated for several values of the electron transfer coefficients $\alpha$. A) $n=1$ and B) $n=2$. The other simulation conditions are: $E_{\mathrm{sw}}=50 \mathrm{mV}$, $\Delta E=4 \mathrm{mV}, T=298 \mathrm{~K}$ 

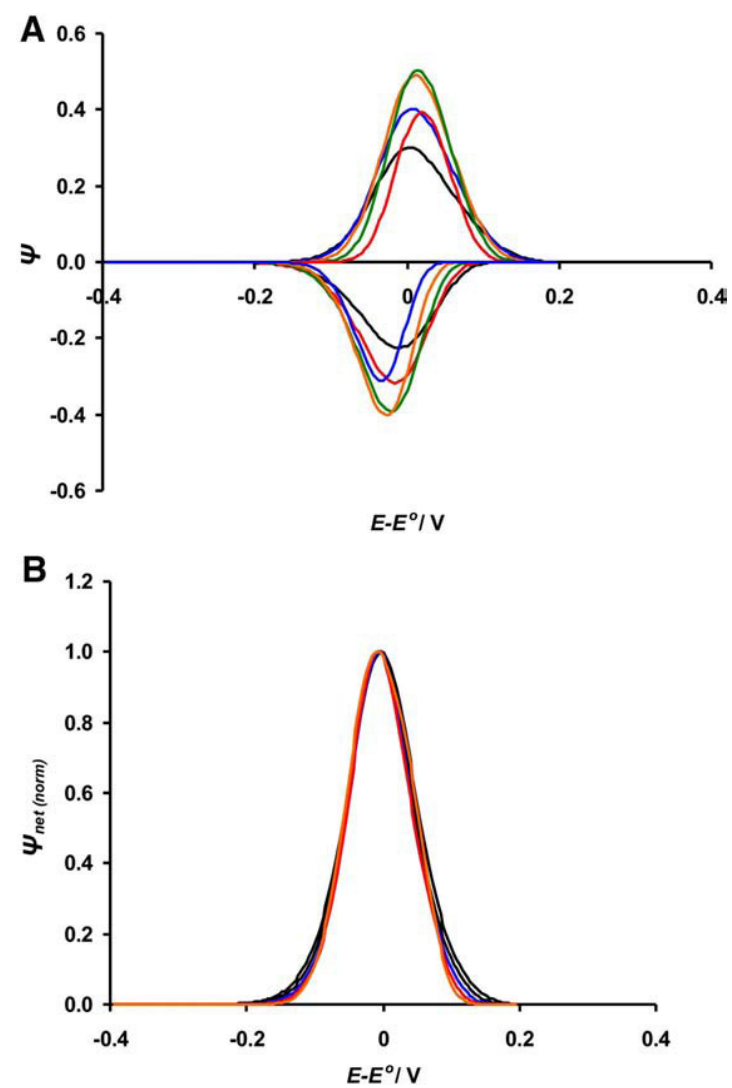

Fig. 9. Surface redox reaction: A) Effect of the kinetic parameter $K$ to the shape of the forward and backward current components of the simulated voltammograms. The net SW voltammograms in B) are normalized, and they show the effect of $K$ to their halfpeak width. $\ln (K)=-1.15$ (green), -0.69 (red) -0.23 (black), 0.23 (pink) and 0.69 (blue). All the other simulation details are identical as those in Fig. 8. (For interpretation of the references to color in this figure legend, the reader is referred to the web version of this article.)

the half-peak widths $\Delta E_{\mathrm{p} / 2}$ and $\ln (K)$ in the quasireversible region of electron transfer are given in Table 1 (for $n=1$ and $n=2$ and several square-wave amplitudes and $\alpha$ values). The equations given in Table 1 can be routinely used for quick determination of the standard rate constant of electron transfer $k_{\mathrm{s}}$ from the simple half-peak widths measurements of the experimental square-wave voltammograms. This is a very simple approach for precise determination of the standard rate constant of the electrode reaction.

In the real experiment, one needs to measure the half-peak width only for a given set of parameters of the potential modulation. With a help of equations listed in Table 1, one can calculate the value of the electrode kinetic parameter $K$, provided that $n, \alpha$, and $D$ are already known. From the definition of the electrode kinetic parameter, it follows that the standard rate constant of the electrode reaction can be calculated from the following simple relation: $k_{\mathrm{s}}=K \sqrt{D f}$. This procedure has been applied for a series of experimental systems presented in the literature listed in Table 3A. The standard rate constants measured with other SW voltammetric methods (third column) are compared to the values estimated with the approach presented here (fourth column).

2.2. Sensitivity of the half-peak widths of SW voltammograms by the surface redox reactions

In this part we elaborate the half-peak width features of theoretical SW voltammograms of a simple surface electrode reaction that can be described by following reaction scheme:

$\mathrm{A}_{\text {(adsorbed) }}+n \mathrm{e}^{-} \Leftrightarrow \mathrm{B}_{\text {(adsorbed) }}$
Both, the reactant $\mathrm{A}$ and the product B are strongly adsorbed to the surface of electrode surface, so that the mass transport can be completely neglected. All general principles of part A can also be applied to the surface electrode reaction. Again, for a constant temperature, the magnitudes of the half-peak widths of the simulated square-wave voltammograms depend in the same way on $n, \alpha$, and the kinetic parameter $K$ (in this situation $K$ is defined as $K=k_{\mathrm{s}} / f$ ). Similar to the case of a dissolved redox couple, the dependence $\Delta E_{\mathrm{p} / 2}$ $v s . T$ in the irreversible kinetic region can be used for the determination of electron transfer coefficient $\alpha$ (see Fig. 7). Theoretical curves of the half-peak widths $\Delta E_{\mathrm{p} / 2}$ as function of the kinetic parameter $\ln (K)$ are calculated for several values of $\alpha$ and $n=1$ and $n=2$ and are presented in Fig. $8 \mathrm{~A}$ and B, respectively. For the case of a very slow electron transfer reaction $(\ln (K)<-2)$, and for fast electron transfers $(\ln (K)>-0.2)$ the magnitude of the theoretical half-peak widths are insensitive to $K$ (it is important to stress that in the regions of very fast electron transfers $(\ln (K)>0.2)$, the net SW peak splits into two peaks, a phenomenon discussed elsewhere) $[3,12,27]$. Within these two kinetic regions i.e. $-2<\ln (K)<-0.2$, the half-peak widths of theoretical net square-wave voltammograms decrease considerably by increasing of the value of $\ln (K)$. The effect of the $K$ to the forward, backward and net components of the theoretical SW voltammograms in the quasireversible region of electron transfer can be easily obtained from the voltammograms presented in Fig. $9 \mathrm{~A}$ and B, respectively. The slopes of the linear parts of the theoretical curves presented in Fig. 8A and $\mathrm{B}$ are again inversely proportional to the values of $\alpha$. The equations corresponding to the region of the linear dependence between $\Delta E_{\mathrm{p} / 2}$ and $\ln (K)$ are given in Table 2 . As for the case of redox reactions taking place from dissolved state, the equations given in Table 2 can be used for a very simple and precise determination of the value of the standard rate constant of electron transfer $k_{\mathrm{s}}$ and even from the single measurements of the half-peak widths of the experimental

Table 2

Simple surface redox reaction

A. Equations of the linear dependences between the SW half-peak width $\Delta E_{\mathrm{p} / 2}$ and ln $(K)$ in quasireversible region. SW voltammograms were simulated for $T=298 \mathrm{~K}$, $\Delta E=2 \mathrm{mV}, n=1$

\begin{tabular}{|c|c|c|c|}
\hline$T / \mathrm{K}$ & $\alpha$ & $n E_{\mathrm{sw}} / \mathrm{mV}$ & Equation of the dependence $\Delta E_{\mathrm{p} / 2}-\ln (K)$ \\
\hline \multirow[t]{15}{*}{298.15} & \multirow[t]{3}{*}{0.3} & 30 & $\Delta E_{\mathrm{p} / 2} / \mathrm{mV}=-18.40 \ln (K)+85.00$ \\
\hline & & 40 & $\Delta E_{\mathrm{p} / 2} / \mathrm{mV}=-18.80 \ln (K)+100.00$ \\
\hline & & 50 & $\Delta E_{\mathrm{p} / 2} / \mathrm{mV}=-17.40 \ln (K)+105.00$ \\
\hline & \multirow[t]{3}{*}{0.4} & 30 & $\Delta E_{\mathrm{p} / 2} / \mathrm{mV}=-16.90 \ln (K)+85.00$ \\
\hline & & 40 & $\Delta E_{\mathrm{p} / 2} / \mathrm{mV}=-16.60 \ln (K)+100.00$ \\
\hline & & 50 & $\Delta E_{\mathrm{p} / 2} / \mathrm{mV}=-13.70 \ln (K)+105.00$ \\
\hline & \multirow[t]{3}{*}{0.5} & 30 & $\Delta E_{\mathrm{p} / 2} / \mathrm{mV}=-11.20 \ln (K)+85.00$ \\
\hline & & 40 & $\Delta E_{\mathrm{p} / 2} / \mathrm{mV}=-08.80 \ln (K)+95.00$ \\
\hline & & 50 & $\Delta E_{\mathrm{p} / 2} / \mathrm{mV}=-08.10 \ln (K)+100.00$ \\
\hline & \multirow[t]{3}{*}{0.6} & 30 & $\Delta E_{\mathrm{p} / 2} / \mathrm{mV}=-12.40 \ln (K)+85.00$ \\
\hline & & 40 & $\Delta E_{\mathrm{p} / 2} / \mathrm{mV}=-10.90 \ln (K)+95.00$ \\
\hline & & 50 & $\Delta E_{\mathrm{p} / 2} / \mathrm{mV}=-10.30 \ln (K)+100.00$ \\
\hline & \multirow[t]{3}{*}{0.7} & 30 & $\Delta E_{\mathrm{p} / 2} / \mathrm{mV}=-7.40 \ln (K)+85.00$ \\
\hline & & 40 & $\Delta E_{\mathrm{p} / 2} / \mathrm{mV}=-8.90 \ln (K)+95.00$ \\
\hline & & 50 & $\Delta E_{\mathrm{p} / 2} / \mathrm{mV}=-7.10 \ln (K)+95.00$ \\
\hline \multicolumn{4}{|c|}{ B. $n=2$. All the other conditions are same as those by panel A } \\
\hline \multirow[t]{15}{*}{298.15} & \multirow[t]{3}{*}{0.3} & 30 & $\Delta E_{\mathrm{p} / 2} / \mathrm{mV}=-50.00 \ln (K)+60.00$ \\
\hline & & 40 & $\Delta E_{\mathrm{p} / 2} / \mathrm{mV}=-54.00 \ln (K)+62.00$ \\
\hline & & 50 & $\Delta E_{\mathrm{p} / 2} / \mathrm{mV}=-48.50 \ln (K)+62.00$ \\
\hline & \multirow[t]{3}{*}{0.4} & 30 & $\Delta E_{\mathrm{p} / 2} / \mathrm{mV}=-27.50 \ln (K)+54.00$ \\
\hline & & 40 & $\Delta E_{\mathrm{p} / 2} / \mathrm{mV}=-27.50 \ln (K)+60.00$ \\
\hline & & 50 & $\Delta E_{\mathrm{p} / 2} / \mathrm{mV}=-25.00 \ln (K)+60.00$ \\
\hline & \multirow[t]{3}{*}{0.5} & 30 & $\Delta E_{\mathrm{p} / 2} / \mathrm{mV}=-15.00 \ln (K)+52.00$ \\
\hline & & 40 & $\Delta E_{\mathrm{p} / 2} / \mathrm{mV}=-16.50 \ln (K)+56.00$ \\
\hline & & 50 & $\Delta E_{\mathrm{p} / 2} / \mathrm{mV}=-12.50 \ln (K)+56.00$ \\
\hline & \multirow[t]{3}{*}{0.6} & 30 & $\Delta E_{\mathrm{p} / 2} / \mathrm{mV}=-07.50 \ln (K)+50.00$ \\
\hline & & 40 & $\Delta E_{\mathrm{p} / 2} / \mathrm{mV}=-10.00 \ln (K)+52.00$ \\
\hline & & 50 & $\Delta E_{\mathrm{p} / 2} / \mathrm{mV}=-07.50 \ln (K)+52.00$ \\
\hline & \multirow[t]{3}{*}{0.7} & 30 & $\Delta E_{\mathrm{p} / 2} / \mathrm{mV}=-05.00 \ln (K)+50.00$ \\
\hline & & 40 & $\Delta E_{\mathrm{p} / 2} / \mathrm{mV}=-07.00 \ln (K)+52.00$ \\
\hline & & 50 & $\Delta E_{\mathrm{p} / 2} / \mathrm{mV}=-05.00 \ln (K)+50.00$ \\
\hline
\end{tabular}


voltammograms, providing that the values of $n$ and $\alpha$ are known. This method can be regarded as a viable alternative for the methods of "quasireversible maximum" and "splitting SW peaks" [3] for accessing the kinetic parameters of the simple surface redox reactions featuring moderate electron transfers.

\section{Conclusions}

The demands for rapid and precise determinations of the kinetic parameters of electron (charge) transfer reactions by many biologically important redox systems require development of simple and reliable methods. To date, the majority of the physical parameters characterizing the electron transfer reactions by various biologically relevant redox systems have been commonly accessed from the cyclovoltammetric experiments [2]. The recent developments of several theoretical works analyzing different redox systems studied under conditions of square-wave voltammetry provided a large number of elegant methods for assessing a variety of thermodynamic and kinetics parameters [3,27]. Generally, the magnitudes of the SW peak potentials and the SW peak currents, analyzed as a function of the time (frequency), have been explored as main items for the determination of the kinetic parameters of the electron transfer reactions [3]. In this work, we present a theoretical set of results, which shows that the half-peak width of the net square-wave voltammograms can be used as a method for quick and reliable determination of the physical parameters characterizing the electron transfer reactions of a dissolved state and on the electrode surface reactions. With the help of the theoretical equations given in the Tables 1 and 2, we have estimated the standard rate constant $k_{\mathrm{s}}$ of numerous biologically relevant redox systems, by using this new method based on the halfpeak width measurements. The estimated values of $k_{\mathrm{s}}$ are given in Table $3 \mathrm{~A}$ and $\mathrm{B}$, together with the $k_{\mathrm{s}}$ values from the square-wave voltammetric experiments determined by other authors. Obviously, the estimated $k_{\mathrm{s}}$ values are consistent with those derived from other square-wave voltammetric methods. The small discrepancies that appear between the experimentally determined and the theoretically calculated data of $k_{\mathrm{s}}$ in Table $3 \mathrm{~A}$ and $\mathrm{B}$ fall within the range of statistical errors of the applied experimental methodologies. This shows that the half-peak width measuring method of the SW voltammograms can be successfully explored as a routine tool for rapid and precise determination of the kinetic parameters of electron transfer reactions featuring moderate electron transfers. Moreover, it can be also seen as a simple and viable alternative for the other voltammetric methods developed for kinetics characterizations of the electron transfer rates, as well as for assessing the ion-transfer kinetics by the four-electrode experiments of ion transfer across the liquid-liquid interface [3,5]. In particular, the method can be of a significant importance for the kinetic characterizations of the electron transfer rates by surface-confined metalo-protein reactions studied with protein-film voltammetry [8-10,28-30]. The main advantage of this method, against the familiar cylco-voltammetric method based on the dependence of the peak-topeak separation as a function of the scan rate [2], is the avoidance of the IR drop effect, which is inevitably present when using large scan-rates in cyclo-voltammetric measurements. By using the corresponding equations given in Tables 1 and 2, we give a simple and easy method to determine the kinetic parameters of various charge-transfer reactions without making comprehensive frequency analysis, thus avoiding the undesired IR drop effects to the charge-transfer kinetics [3].

At the end, it is worth to mention once again that the estimation of the standard rate constants of electron transfer with the help of theoretical equations given in Tables 1 and 2 relies to the previously determined values of the electron transfer coefficient $\alpha$ (by both considered redox mechanisms), and the diffusion coefficient $D$ (by the redox reaction from dissolved state). For the determination of electron

Table 3

Experimental and theoretical values of the standard rate constants of electron transfer of some redox systems

A. From dissolved state. The theoretical values were estimated from the half-peak width of square-wave voltammograms by using corresponding equations given in Table 1

\begin{tabular}{|c|c|c|c|c|}
\hline \multirow[t]{2}{*}{ Compound } & \multirow[t]{2}{*}{ Experimental conditions } & \multirow{2}{*}{$\begin{array}{l}\text { Experimental } \\
k_{\mathrm{s}} / \mathrm{cm} \mathrm{s}^{-1}\end{array}$} & \multirow{2}{*}{$\begin{array}{l}\text { Theoretical } \\
k_{\mathrm{s}} / \mathrm{cm} \mathrm{s}^{-1}\end{array}$} & \multirow[t]{2}{*}{ Reference } \\
\hline & & & & \\
\hline$\overline{\mathrm{Eu}^{3+}}$ & Mercury electrode, $0.01 \mathrm{M} \mathrm{HClO}_{4}$ & $0.006 \pm 0.001$ & $0.005 \pm 0.001$ & [32] \\
\hline Cercosporin & Glassy carbon electrode, $1 \mathrm{M} \mathrm{HClO}_{4}+\mathrm{ACN}$ & $0.019 \pm 0.005$ & $0.025 \pm 0.004$ & [33] \\
\hline $\mathrm{ZnCl}^{+}$ & Mercury electrode, $\mathrm{pH}=2\left(\mathrm{NaClO}_{4}+\mathrm{HClO}_{4}\right)$ & $0.0045 \pm 0.0005$ & $0.0035 \pm 0.00045$ & [34] \\
\hline $\mathrm{La}^{3+}$ & Tungsten Electrode, Molten-chlorides mixtures & $0.004 \pm 0.001$ & $0.006 \pm 0.0005$ & [35] \\
\hline $\mathrm{Y}^{3+}$ & Tungsten Electrode, Molten-chlorides mixtures & $0.0037 \pm 0.001$ & $0.0045 \pm 0.0005$ & [35] \\
\hline $\left.\mathrm{Re}_{6} \mathrm{Se}_{8}\left(\mathrm{CH}_{3} \mathrm{CN}\right)_{6}\right]^{2+}$ & Pt electrode, Propylene carbonate & $0.0035 \pm 0.0015$ & $0.00315 \pm 0.0035$ & [36] \\
\hline $\mathrm{Zn}^{2+}$ & Mercury electrode $\mathrm{pH}=7$ & $0.00026 \pm 0.00016$ & $0.00020 \pm 0.0001$ & [37] \\
\hline 2-[[2-hydroxyethyl)amino]ethyl]amino]-1-4-naphtoquinone & Mercury electrode $N, N$-dimethylformamide & $0.041 \pm 0.014$ & $0.025 \pm 0.01$ & [38] \\
\hline 2-[[2-dimethyl)amino]ethyl]amino]-1-4-naphtoquinone & Mercury electrode $N, N$-dimethylformamide & $0.041 \pm 0.013$ & $0.025 \pm 0.01$ & [38] \\
\hline 2-chloro-3-[[2-dimethyl)amino]ethyl]amino]-1-4-naphtoquinone & Mercury electrode $N, N$-dimethylformamide & $0.051 \pm 0.019$ & $0.04 \pm 0.012$ & [38] \\
\hline 1,4-dixidroxy-5,8-bis[[2-hydroxyethyl)amino]ethyl]amino]-anthraquinone & Mercury electrode $N, N$-dimethylformamide & $0.014 \pm 0.007$ & $0.009 \pm 0.0015$ & [38] \\
\hline
\end{tabular}

B. Surface reactions. The theoretical values were estimated from the half-peak width of square-wave voltammograms by using corresponding equations given in Table 2

\begin{tabular}{|c|c|c|c|c|}
\hline \multirow[t]{2}{*}{ Compound } & \multirow[t]{2}{*}{ Experimental conditions } & \multirow{2}{*}{$\frac{\text { Experimental }}{k_{\mathrm{s}} / \mathrm{s}^{-1}}$} & \multirow{2}{*}{$\begin{array}{l}\text { Theoretical } \\
k_{\mathrm{s}} / \mathrm{s}^{-1}\end{array}$} & \multirow[t]{2}{*}{ Reference } \\
\hline & & & & \\
\hline Cynolline & Mercury electrode, $\mathrm{pH}=7.0$ & $455 \pm 110$ & $360 \pm 40$ & [39] \\
\hline Azobenzene & Mercury electrode, $\mathrm{pH}=4.65$ & $28 \pm 10$ & $35 \pm 5$ & {$[40]$} \\
\hline $\mathrm{Mo}(\mathrm{VI})$-fulvic acid complex in the presence of phenantroline & Mercury electrode, $\mathrm{pH}=2.0$ & $8 \pm 2$ & $18 \pm 4$ & [41] \\
\hline Myoglobin & $\begin{array}{l}\text { Plane pyrolitic graphite electrode modified with } \\
\text { film of didodecylmethylammonium bromide }\end{array}$ & $48 \pm 2$ & $33 \pm 5$ & [42] \\
\hline Cytochrome C & ITO electrode, & $8.4 \pm 2$ & $4.80 \pm 1.5$ & [43] \\
\hline Hemoglobin-AQ55 & $\begin{array}{l}\text { Pyrolitic graphite electrode modified } \\
\text { with polyester sulfonic acid }\end{array}$ & $60 \pm 10$ & $39.70 \pm 6$ & [44] \\
\hline 2-Hydroxy-5-[(4-sulfophenyl)azo]benzoic acid & Mercury electrode, $\mathrm{pH}=4.00$ & $24 \pm 6$ & $21.80 \pm 4$ & [45] \\
\hline Adriamycin & Mercury electrode $\mathrm{pH}=4.65$ & $49 \pm 12$ & $42.80 \pm 8$ & [46] \\
\hline Cd(II)-Ferron complex & Mercury electrode $\mathrm{pH}=10.80$ & $0.17 \pm 0.01$ & $1.00 \pm 0.5$ & [47] \\
\hline 4-(dimethylamino)-azobenzene & Mercury electrode $\mathrm{pH}=6.00$ & $102 \pm 2$ & $119 \pm 10$ & [48] \\
\hline $\mathrm{Cd}(\mathrm{II})-8-\mathrm{OH}$-quinoline & Mercury electrode $\mathrm{pH}=6.70$ & $7 \pm 1$ & $8.80 \pm 2$ & [49] \\
\hline $\mathrm{Cu}(\mathrm{II})-8-\mathrm{OH}$-quinoline & Mercury electrode $\mathrm{pH}=6.70$ & $1.5 \pm 0.1$ & $2.2 \pm 1.5$ & [49] \\
\hline
\end{tabular}


transfer coefficient $\alpha$ one can use the theoretical equations and approaches described in Figs. 4 and 7, which are also explained in more details in our recent publication [27b]. For the estimation of the values of the diffusion coefficient $D$ one is advised to use the methodologies proposed in references $[2,3]$.

\section{Acknowledgments}

Rubin Gulaboski thanks Alexander von Humboldt Stiftung for providing a postdoctoral fellowship.

This project was funded by two competitive research grants from the Saarland University (HOMFOR both to I. Bogeski).

\section{Appendix A. Mathematical model and simulation details Redox reaction from dissolved state}

A quasireversible electrode reaction of two chemically stable species dissolved in the electrolyte solution is described by:

$\mathrm{A}_{(\text {dissolved })}+n \mathrm{e}^{-} \Leftrightarrow \mathrm{B}_{(\text {dissolved })}$

The electrode mechanism (I) can be described mathematically by the following set of equations:

$\frac{\partial c(\mathrm{~A})}{\partial t}=D\left(\frac{\partial^{2} c(\mathrm{~A})}{\partial x^{2}}\right)$

$\frac{\partial c(\mathrm{~B})}{\partial t}=D\left(\frac{\partial^{2} c(\mathrm{~B})}{\partial x^{2}}\right)$

$t=0, x \rightarrow \alpha: c(\mathrm{~A})=c(\mathrm{~A}) * ;(\mathrm{B})=0$

$t>0, x \rightarrow \propto: c(\mathrm{~A})+c(\mathrm{~B})=c(\mathrm{~A})^{*} ; c(\mathrm{~A}) \rightarrow c(\mathrm{~A})^{*}, c(\mathrm{~B}) \rightarrow 0$

$t>0, x=0: D\left(\frac{\partial c(\mathrm{~A})}{\partial x}\right)_{x=0}=-D\left(\frac{\partial c(\mathrm{~B})}{\partial x}\right)_{x=0}=\frac{I}{n F S}$

$c(\mathrm{~A})$ and $c(\mathrm{~B})$ are the concentrations of the species $\mathrm{A}$ and $\mathrm{B}$, while $c(\mathrm{~A})^{*}$ is the bulk concentration of $A$. $I$ is symbol of the current, $S$ is the electrode surface area $\left(\mathrm{cm}^{2}\right)$, and $D$ is the diffusion coefficient $\left(\mathrm{cm}^{2} \mathrm{~s}^{-1}\right)$ which is assumed to be equal for both $\mathrm{A}$ and $\mathrm{B}$. In the case of the charge-transfer controlled redox reaction, at the electrode surface the following condition holds:

$\frac{I}{n F S}=k_{\mathrm{S}} \exp (-\alpha \phi)\left[c(\mathrm{~A})_{x=0}-\exp (\phi) c(\mathrm{~B})_{x=0}\right]$

In Eq. (5) with $k_{\mathrm{s}}\left(\mathrm{cm} \mathrm{s}^{-1}\right)$ is assigned the heterogeneous electron exchange rate constant corresponding to the standard redox potential $E_{\mathrm{A} / \mathrm{B}}^{\ominus}$ of the electrode reaction (I), $\alpha$ is the cathodic electron transfer coefficient, and $\phi=\frac{n F}{R T}\left(E-E_{\mathrm{A} / \mathrm{B}}^{\ominus}\right)$ is the dimensionless relative electrode potential. The symbols for $n, F, R$ and $T$ are the number of exchanged electrons, the Faraday constant, the universal gas constant and the temperature, respectively. The solutions for $c(\mathrm{~A})$ and $c(\mathrm{~B})$ at the electrode surface have been obtained with help of Laplace transformations and they read:

$c(\mathrm{~A})_{x=0}=c(\mathrm{~A})^{*}-\frac{1}{\sqrt{\pi}} \int_{0}^{t} \frac{I(\tau)}{n F S \sqrt{D}} \frac{\mathrm{d} \tau}{\sqrt{(t-\tau)}}$

$c(\mathrm{~B})_{x=0}=\frac{1}{\sqrt{\pi}} \int_{0}^{t} \frac{I(\tau)}{n F S \sqrt{D}} \frac{\mathrm{d} \tau}{\sqrt{(t-\tau)}}$
By substituting Eqs. (6) and (7) into Eq. (5) one gets the integral Eq. (8) that represents mathematically the quasireversible electrode reaction of a dissolved redox couple under voltammetric conditions:

$$
\begin{aligned}
\frac{I}{n F S}= & k_{\mathrm{S}} \exp (-\alpha \phi) \\
& \times\left[c(\mathrm{~A}) *-\frac{1}{\sqrt{\pi}} \int_{0}^{t} \frac{I}{n F S \sqrt{D}} \frac{1}{\sqrt{(t-\tau)}} d \tau-\exp (\phi) \frac{1}{\sqrt{\pi}} \int_{0}^{t} \frac{I}{n F S \sqrt{D}} \frac{1}{\sqrt{(t-\tau)}} d \tau\right]
\end{aligned}
$$

The solution of Eq. (8) under conditions of square-wave voltammetry was obtained with the help of numerical method proposed by Nicholson and Olmstead [31]. Both, the time variable and dimensionless current were discretized. To each time period $t=j d$, where $d$ is the time increment, a certain current $\Psi_{j}$ can be ascribed. The numerical solution for Eq. (8) reads:

$\psi_{j}=\frac{K \exp \left(-\alpha \phi_{j}\right)\left[1-\frac{2}{\sqrt{50 \pi}}\left(1+\exp \left(\phi_{j}\right)\right) \sum_{i=1}^{j-1} \psi_{i} S_{j-i+1}\right]}{1+2 K \exp \left(-\alpha \phi_{j}\right)\left[\sqrt{50 \pi}\left(1+\exp \left(\phi_{j}\right)\right)\right]}$

where $S_{j}=\sqrt{j}-\sqrt{j-1}$, and $K$ is the dimensionless kinetic parameter defined as $K=\frac{k_{\mathrm{s}}}{\sqrt{D f}}$. For the calculations, the time increment $d=1 /(50 f)$ was used, which means that each SW half-period was divided into 25 increments. The dimensionless current $\Psi$ is normalized as: $\psi=\frac{I}{n F S c(\mathrm{~A}) * \sqrt{f D}}$. A comprehensive study of this redox mechanism can be found elsewhere [3,13].

\section{Appendix B. Surface electrode reaction}

In the second case, we consider surface-confined (diffusionless) electrode reaction of strongly adsorbed redox couple that can be represented by following reaction scheme:

$\mathrm{A}_{(\text {adsorbed })}+n \mathrm{e}^{-} \Leftrightarrow \mathrm{B}_{(\text {adsorbed })}$

It is assumed that all participants in the electrode mechanism (II) are strongly adsorbed on the electrode surface. During the voltammetric experiment the mass transport of all species is neglected. The electrode mechanism (II) is mathematically represented by the following set of equations:

$\mathrm{d} \Gamma(\mathrm{A}) / \mathrm{d} t=-I /(n F S)$

$\mathrm{d} \Gamma(\mathrm{B}) / \mathrm{d} t=I /(n F S)$

$t=0 ; \Gamma(\mathrm{A})=\Gamma(\mathrm{A})^{*} ; \Gamma(\mathrm{B})=0$

$t>0 ; \Gamma(\mathrm{A})+\Gamma(\mathrm{B})=\Gamma(\mathrm{A})^{*}$

$\Gamma$ is a symbol of the surface concentration, which is a function of time $t$, whereas $\Gamma(\mathrm{A}) *$ is the total surface concentration of all species. The solutions are:

$\Gamma(\mathrm{A})=\Gamma(\mathrm{A})^{*}-\int_{0}^{t} \frac{I(\tau)}{n F S} \mathrm{~d} \tau$

$\Gamma(\mathrm{B})=\int_{0}^{t} \frac{I(\tau)}{n F S} \mathrm{~d} \tau$ 
Considering again the Buttler-Volmer formalism, at the electrode surface the following condition applies:

$\frac{I}{n F S}=k_{\mathrm{S}} \exp (-\alpha \phi)[\Gamma(\mathrm{A})-\exp (\phi) \Gamma(\mathrm{B})]$

where $k_{\mathrm{s}}\left(\mathrm{s}^{-1}\right)$ is the heterogeneous electron exchange rate constant corresponding to the standard redox potential $E_{\mathrm{A} / \mathrm{B}}^{\ominus}$, while other symbols have the same meaning as in the previous model. $\phi=\frac{n F}{R T}\left(E-E_{\mathrm{A} / \mathrm{B}}^{\ominus}\right)$.

Substituting Eqs. (14) and (15) into Eq. (16) yields:

$$
\frac{I}{n F S}=k_{S} \exp (-\alpha \phi)\left[\Gamma(\mathrm{A})^{*-} \int_{0}^{t} \frac{I(\tau)}{n F S} \mathrm{~d} \tau-\exp (\phi) \int_{0}^{t} \frac{I(\tau)}{n F S} \mathrm{~d} \tau\right]
$$

Integral Eq. (16) is a general mathematical solution of the simple surface electrode mechanism. Numerical solution according to the method of Nicholson and Olmstead [31] is:

$\psi=\frac{K \exp \left(-\alpha \phi_{m}\right)\left[1-\frac{1+\exp \left(\phi_{m}\right)}{50} \sum_{j=1}^{m-1} \psi_{j}\right]}{1+\frac{\exp \left(-\phi_{m}\right)}{50}\left[1+\exp \left(\phi_{m}\right)\right]}$

In this case, the dimensionless redox kinetic parameter $K$ is defined as $K=k_{\mathrm{s}} / f$, while the dimensionless current $\Psi$ is normalized as $\psi=\frac{I}{\operatorname{nFST}(\mathrm{A})^{*} f}$.

All the simulations have been performed with the help of the MATHCAD software.

\section{References}

[1] J.G. Osteryoung, R.A. Osteryoung, Square-wave voltammetry, Anal. Chem. 57 (1985) A101-A110.

[2] A.J. Bard, L.R. Faulkner, Electrochemical Methods, Fundamentals and Applications, ed., John Wiley \& Sons, New York, 2001.

[3] V. Mirceski, S. Komorsky-Lovric, M. Lovric, in: F. Scholz (Ed.), Square-Wave Voltammetry, Theory and Application, Springer, Berlin, 2008.

[4] E.T. Smith, B.A. Feinberg, Redox properties of several bacterial ferredoxins using square-wave voltammetry, J. B. Chem. 265 (1990) 14371-14376.

[5] F. Scholz, U. Schröder, R. Gulaboski, Electrochemistry of Immobilized Particles and Droplets, Springer, Berlin, 2005.

[6] N.F. Hu, Direct electrochemistry of redox proteins or enzymes at various film electrodes and their possible applications in monitoring some pollutants, Pure App. Chem. 73 (2001) 1979-1991.

[7] Y.H. Wu, S.S. Hu, Biosensors based on direct electron transfer in redox proteins, Microchim. Acta 159 (2007) 1-17.

[8] F.A. Armstrong, Bioelectrochemistry of Biomacromolecules, Birkhauser, Basel, 1997.

[9] F.A. Armstrong, H.A. Heering, J. Hirst, Reactions of complex metalloproteins studied by protein-film voltammetry, Chem. Soc. Rev. 26 (1997) 169-179.

[10] C. Leger, S.J. Elliott, K.R. Hoke, L.J.C. Jeuken, A.K. Jones, F.A. Armstrong, Enzyme electrokinetics: using protein film voltammetry to investigate redox enzymes and their mechanisms, Biochem. 42 (2003) 8653-8662.

[11] P. Obrien, D.A. Sweigart, Low-temperature electrochemistry of chromium porphyrins - characterization of transient species, J. Chem. Soc., Chem. Commun. (1986) 198-200.

[12] J.J. Odea, J.G. Osteryoung, Characterization of quasi-reversible surface processes by square-wave voltammetry, Anal. Chem. 65 (1993) 3090-3097.

[13] J.J. Odea, J. Osteryoung, R.A. Osteryoung, Theory of square-wave voltammetry for kinetic systems, Anal. Chem. 53 (1981) 695-701.

[14] F. Garay, M. Lovric, Quasi-reversible EC reactions at spherical microelectrodes analysed by square-wave voltammetry, J. Electroanal. Chem. 527 (2002) 85-92.

[15] F. Garay, M. Lovric, Square-wave voltammetry of quasi-reversible electrode processes with coupled homogeneous chemical reactions, J. Electroanal. Chem. 518 (2002) 91-102.

[16] A.B. Miles, R.G. Compton, The theory of square wave voltammetry at uniformly accessible hydrodynamic electrodes, J. Electroanal. Chem. 487 (2000) 75-89.

[17] A.B. Miles, R.G. Compton, Simulation of square-wave voltammetry at a channel electrode: E, EC and ECE processes, J. Electroanal. Chem. 499 (2001) 1-16.

[18] B.A. Brookes, R.G. Compton, Simulation of square wave voltammetry: quasireversible electrode processes, J. Phys. Chem. B 103 (1999) 9020-9028.

[19] V. Mirceski, R. Gulaboski, Surface catalytic mechanism in square-wave voltammetry, Electroanalysis 13 (2001) 1326-1334.
[20] V. Mirceski, M. Lovric, Adsorption effects in square-wave voltammetry of an EC mechanism, Croat. Chem. Acta 73 (2000) 305-329.

[21] R. Gulaboski, V. Mirceski, S. Komorsky-Lovric, M. Lovric, Square-wave voltammetry of cathodic stripping reactions. Diagnostic criteria, redox kinetic measurements, and analytical applications, Electroanalysis 16 (2004) 832-842.

[22] V. Mirceski, M. Lovric, EC mechanism of an adsorbed redox couple. Volume vs surface chemical reaction, J. Electroanal. Chem. 565 (2004) 191-202.

[23] V. Mirceski, Charge transfer kinetics in thin-film voltammetry. Theoretical study under conditions of square-wave voltammetry, J. Phys. Chem. B 108 (2004) 13719-13725.

[24] V. Mirceski, Square-wave voltammetry of an EC reaction of a partly adsorbed redox couple, J. Electroanal. Chem. 508 (2001) 138-149.

[25] E. Laviron, Adsorption, autoinhibition and autocatalysis in polarography and in linear potential sweep voltammetry, J. Electroanal. Chem. 52 (1974) 355-393.

[26] E. Laviron, Use of linear potential sweep voltammetry and of AC voltammetry for the study of the surface electrochemical reaction of strongly adsorbed systems and of redox modified electrodes, J. Electroanal.Chem. 100 (1979) 263-270.

[27] a) V. Mirceski, M. Lovric, Split square-wave voltammograms of surface redox reactions, Electroanalysis 9 (1997) 1283-1287;

b) R. Gulaboski, M. Lovric, V. Mirceski, I. Bogeski, M. Hoth, Protein-film voltammetry: a theoretical study of the temperature effect using square-wave voltammetry, Biophys. Chem. 137 (2008) 49-55

[28] L.J.C. Jeuken, J.P. McEvoy, F.A. Armstrong, Insights into gated electron-transfer kinetics at the electrode-protein interface: a square wave voltammetry study of the blue copper protein azurin, J. Phys. Chem. B 106 (2002) 2304-2313.

[29] J. Hirst, F.A. Armstrong, Fast-scan cyclic voltammetry of protein films on pyrolytic graphite edge electrodes: Characteristics of electron exchange, Anal. Chem. 70 (1998) 5062-5071.

[30] J.P. McEvoy, F.A. Armstrong, Protein film cryovoltammetry: demonstrations with a 7Fe ([3Fe-4S]+[4Fe-4S]) ferredoxin, Chem. Commun. (1999) 1635-1636.

[31] R.S. Nicholson, M.L. Olmsetad, Electrochemistry: Calculations, Simulation and Instrumentation, Marcel Dekker, New York, 1972.

[32] M. Zelic, Reverse scan as a source of information in square wave voltammetry, Croat. Chem. Acta 79 (2006) 49-55.

[33] M.A. Zon, N.C. Marchiando, H. Fernandez, A study of the bielectronic electroreduction of cercosporin phytotoxin in highly acidic non-aqueous medium, J. Electroanal. Chem. 465 (1999) 225-233.

[34] S. Komorsky-Lovric, M. Branica, Effects of surface-active substances in squarewave voltammetry and potentiometric stripping analysis of amalgam-forming metal-ions, Fresenius J. Anal. Chem. 349 (1994) 633-638.

[35] Y. Castrillejo, M.R. Bermejo, E. Barrado, A.M. Martinez, P.D. Arocas, Solubilization of rare earth oxides in the eutectic $\mathrm{LiCl}-\mathrm{KCl}$ mixture at 450 degrees $\mathrm{C}$ and in the equimolar $\mathrm{CaCl} 2-\mathrm{NaCl}$ melt at 550 degrees C, J. Electroanal. Chem. 545 (2003) 141-157.

[36] J.C. Yohannan, Investigation of the photophysical and electrochemical properties of dendrimers based on a [Re6Se8]2+ core, PhD Thesis, 2003 North Carolina State University.

[37] W.S. Go, J.J. Odea, J. Osteryoung, Square-wave voltammetry for the determination of kinetic parameters-the reduction of Zinc(II) at Mercury-electrodes, J. Electroanal. Chem. 255 (1988) 21-44.

[38] C.-Y. Li, J. Jenq, Kinetic study of one-electron reduction of aromatic quinones with aminoalkylamino side chains in $\mathrm{N}, \mathrm{N}$-dimethylformamide by square wave voltammetry and allied techniques, Electrochim. Acta 36 (1991) 269-276.

[39] S. Komorsky-Lovric, Measurement of the kinetics of adsorbed cinnoline by squarewave voltammetry, Anal. Bioanal. Chem. 373 (2002) 777-780.

[40] S. Komorsky-Lovric, M. Lovric, Square-wave voltammetry of quasi-reversible surface redox reactions, J. Electroanal. Chem. 384 (1995) 115-122.

[41] F. Quentel, V. Mirceski, A. Laouenan, C. Elleouet, C.L. Madec, Square-wave voltammetry of the molybdenum-1,10 phenanthroline-fulvic acids complex: redox kinetics measurements, Electroanalysis 15 (2003) 270-277.

[42] A.E.F. Nassar, Z. Zhang, N.F. Hu, J.F. Rusling, T.F. Kumosinski, Proton-coupled electron transfer from electrodes to myoglobin in ordered biomembrane-like films, J. Phys. Chem. B 101 (1997) 2224-2231.

[43] R.T. Hill, Active three-dimensional protein microstructures, PhD Thesis, 2006 University of Texas, Austin.

[44] J. Yang, N.F. Hu, J.F. Rusling, Enhanced electron transfer for hemoglobin in poly (ester sulfonic acid) films on pyrolytic graphite electrodes, J. Electroanal. Chem. 463 (1999) 53-62.

[45] S. Komorsky-Lovric, B. Nigovic, Kinetics of the surface redox reaction of 2-hydroxy5-[(4-sulfophenyl)azo]benzoic acid, Croat. Chem. Acta 78 (2005) 85-90.

[46] S. Komorsky-Lovric, Redox kinetics of adriamycin adsorbed on the surface of graphite and mercury electrodes, Bioelectrochem. 69 (2006) 82-87.

[47] F. Garay, V.M. Solis, Adsorptive square-wave voltammetry for the analysis and speciation of complexes of Cd(II)-ferron, Electroanalysis 16 (2004) 450-457.

[48] J.J. ODea, J.G. Osteryoung, Square wave voltammetry for two step surface reductions, Anal. Chem. 69 (1997) 650-658.

[49] F. Garay, V.M. Solis, Adsorptive square wave voltammetry of metal complexes. Effect of ligand concentration - Part II. Experimental applications, J. Electroanal. Chem. 505 (2001) 109-117. 